\title{
FUNDAMENTOS ÁUREOS DE LA TEORÍA POLÍTICA PLATÓNICA: \\ SOBRE EL MITO DEL 'POLÍTICO’ Y LA \\ TRADICIÓN RELIGIOSA
}

\section{THE GOLDEN-AGE FOUNDATIONS OF PLATONIC POLITICAL THEORY: REGARDING THE MYTH OF THE 'STATESMAN' AND THE RELIGIOUS TRADITION}

\author{
DAVID HeRnÁNDEZ DE LA FuENTE ${ }^{1}$
}

Facultad de Geografia e Historia

UNED

\begin{abstract}
RESUMEN: El presente artículo pretende, tras pasar revista a la bibliografía existente y al estado de la cuestión sobre el mito del Político de Platón, proponer en primer lugar una nueva lectura de este a la luz de la tradición religiosa griega y, concretamente, del Leitmotiv hesiódico del mito de las edades del hombre. En segundo lugar, la comparación de este mito y su trasfondo religioso con otros diálogos políticos del filósofo ateniense, notablemente con las Leyes, revela a nuestro ver a una insistencia en las nociones de la edad de oro y del gobierno divino como ideal político. Considerar este pasaje del Político como un fundamento en el nivel mítico y alusivo para estas nociones en otros diálogos de Platón (sobre todo en las Leyes)
\end{abstract}

${ }^{1}$ Departamento de Historia Antigua. E-mail: dhdelafuente@geo.uned.es 
permitiría, si nuestra hipótesis de trabajo se confirma, ilustrar la interacción del proyecto político global del filósofo con el recurso a la tradición religiosa y con los ejemplos míticos de otros diálogos políticos.

Palabras clave: Filosofía Antigua, Platón, Político, Mito de la Edad de Oro

AвSTRACT: This contribution aims to briefly review the literature and state of the art regarding Plato's Myth of the Statesman and to propose, first, a new reading of this myth in the light of the ancient Greek religious tradition and, specifically, of the Leitmotiv of the Hesiodic Myth of the Ages of Man. Second, we will present a comparison of this myth and its religious background with other political dialogues of the Athenian philosopher, notably with the Laws, which could indicate the notion of the Golden Age and of divine government as a political ideal. The consideration of this passage of the Statesman as a foundation on the mythical and allusive levels for these notions in other dialogues of Plato (especially in the Laws) would, if our working hypothesis is confirmed, illustrate the interaction of the global political project of the philosopher and the use of religious tradition and mythical examples in other political dialogues.

Keywords: Ancient Philosophy, Plato, Statesman, Myth of the Golden Age

\section{Introducción: el mito del político en su contexto}

Esta contribución propone una relectura del conocido mito que inserta $\mathrm{Pla}$ tón en el Político a la luz de los elementos de la tradición mítica y religiosa griega revisando las distintas propuestas interpretativas y realizando una comparación con el tópico de la edad de oro. El mito se encuentra, como es sabido, en un diálogo que versa ante todo sobre la buena techne politike y las características que deben adornar a quien la ejerce, el politikos. Nuestra propuesta quiere ver en este mito una evocación de la cosmología, la historia mítica y la utopía que trasmite la tradición religiosa griega en un contexto político, postulando una influencia de la teología griega en la filosofía política de Platón y, en concreto, la presencia determinante del Leitmotiv religioso tradicional del mito de la edad de oro (que aparece en Trabajos y días de Hesíodo) en el último pensamiento político del filósofo ateniense. 
Después de los numerosos intentos interpretativos de este controvertido pasaje, notablemente y entre otras las lecturas de Skemp (1952), Vidal-Naquet [1978], Castoriadis [2004], Rowe (1995, 2002 y 2010), Brisson (1995) Santa Cruz (2002), Horn (2002), Lisi (1985 y 2004), El Murr (2010 y 2014), y Montserrat (2014), aquí se defenderá que todavía hay que seguir releyendo el mito del Politico en comparación con las fuentes religiosas y las tradiciones utópicas de la literatura griega, algunas de ellas descuidadas, que pueden arrojar luz sobre su intención y su lugar en el pensamiento político de Platón, entre la República y las Leyes. Así, en una primera sección de esta contribución se revisarán los elementos básicos del mito examinando aquellos aspectos que coinciden con la tradición literaria del topos de la Edad de Oro. Hay que dar cuenta en este proceso de las transformaciones de este tema literario y religioso tras la época arcaica y su paso de teleología religiosa a antropología histórica y, finalmente, a tópico político y utópico entre los siglos V y IV a.C. En una segunda sección de esta propuesta esta tradición subyacente tras el propio mito del Político de Platón se pondrá en relación con otros pasajes paralelos del pensamiento político del último Platón y, en concreto, con las Leyes, una comparación que acaso pueda contribuir a aclarar algunas de las perplejidades que ha creado este mito en la historia de su interpretación. Con este recorrido, en fin, se pretende revalorizar la interpretación del mito de un pasado edénico de la humanidad como un tópico político a la luz de la tradición que, desde la época de la tiranía hasta las postrimerías de la Guerra del Peloponeso, hizo un constante uso propagandístico de este tema y, a partir de ahí, reinterpretar el pasaje en cuestión del Político comparándolo con la presencia de ideas recurrentes sobre el mito de las edades y sobre los fundamentos divinos del poder político en otros lugares clave del pensamiento de Platón.

\section{Elementos religiosos y cosmológicos del mito del Político}

Ante todo, procede recordar a modo de resumen de qué manera se aborda el recurso al mito del gobierno divino y de la edad de oro en el Político de Platón. El mito en cuestión se inserta en la discusión después de que el Extranjero de Elea haya tratado de ofrecer una primera definición de la figura del político. En efecto, en un momento de la conversación, que avanza hacia el horismos del 
hombre de estado mediante el procedimiento de la diairesis, se llega a definir al politikos como un "pastor de hombres" (267a-d). Con ello, obviamente, se sigue también una conocida tradición literaria, en el mundo griego, que se remonta a Homero y a su epíteto para caudillos legendarios como Agamenón y que, más allá todavía, recoge una antigua metáfora política muy presente en el mundo semítico y en el antiguo Oriente.

En este punto del diálogo, sin embargo, esta definición llamémosle tradicional aparece como insuficiente, por lo que se opta a continuación por introducir una interesante digresión que propone una explicación mítica de los orígenes para proporcionar una nueva vía que pueda ofrecer resultados satisfactorios. En efecto, ante la vía agotada o interrumpida que se plantea en el desarrollo de la diairesis, el Extranjero de Elea emprende "un nuevo camino" en su conversación con el Joven Sócrates, una senda que ha de ser tomada "desde el principio" ( $\dot{\varepsilon} \xi$

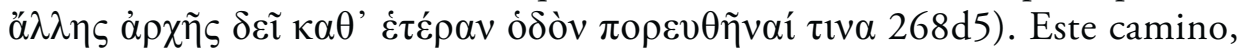
"otro" y a la vez "segundo", consiste, como se dice explícitamente, en el recurso

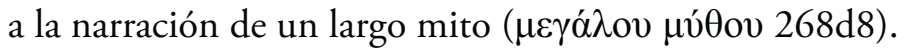

La elección del vocabulario de este segundo intento ya ilustra que las peculiaridades de la vía del mito desde su propia introducción, por lo que debemos reparar preferentemente en ello para entender su nivel alusivo. La consideración de la vía del mito es la de ser "casi un juego" ( $\chi \chi \varepsilon \delta o ̀ v ~ \pi \alpha \imath \delta i \alpha ̀ v ~ 268 \mathrm{~d} 9)$, de manera que se juzga sin duda especialmente apta para el interlocutor, cuya edad

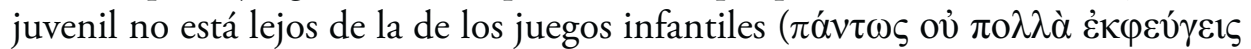

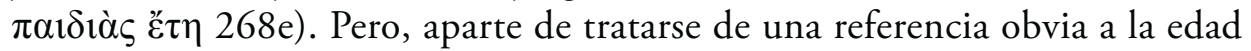
del Joven Sócrates, hay que subrayar otras dos implicaciones de este preámbulo a la narración mítica. Por un lado, el mito requiere de una atención especial, distinta del razonamiento diairético precedente, por parte del oyente, que ha de ser moldeado o educado "desde el principio", como en la infancia, y ha de prestar oídos al relato con una actitud distinta, semejante a la de los niños que

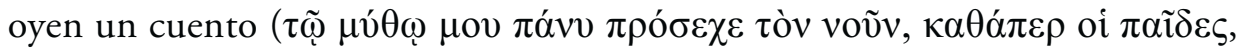
268e4). Se depone así la actitud del razonamiento discursivo y el nous pasa a orientarse ante el narrador de muy diversa forma. Por otro lado, la utilización de la metáfora del juego indica, seguramente, un apunte coincidente con otros pasajes de Platón que, lejos del plano de la broma o la ironía, alude a la seriedad filosófica del mensaje que viene a continuación. Es decir, que el mito que se va a narrar constituye un exemplum para salir del atolladero filosófico en el que se ha detenido la conversación frustrada tendente a la definición del aner politikos. Además de la alusión al "juego", otras indicaciones sobre el nivel de conocimiento y 
percepción que requiere el discurso mítico que va a emprender el Extranjero de

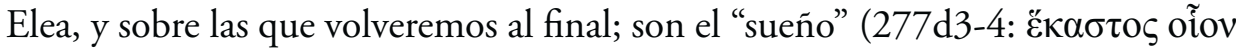

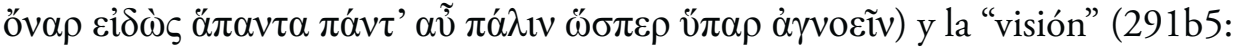

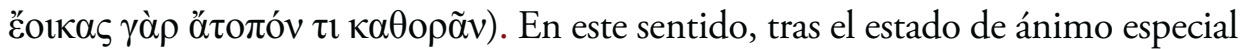
y propio del mito que se sugiere -y que adoptan tanto el narrador, al contar, en palabras de Marcel Detienne, esas viejas historias de la tribu que habitan "en el país de la memoria", como el joven interlocutor, al que se pide un cambio de actitud al escucharlas-, cabe recordar aquí el pasaje clásico en Platón acerca de la consideración de la seriedad y el juego, al que se refiere la Carta VII 344c. Estas características introductorias deberían, por lo menos, ponernos en guardia con respecto a las implicaciones de este interludio mítico en el discurso filosófico, que en absoluto lo invalida como lectura irónica o paródica, sino que, antes al contrario, y como todos los "juegos" platónicos explicados por medio de un mito, tiene consecuencias profundas para la educación del alma del joven oyente.

A grandes rasgos, el mito del Politico describe en tono legendario la historia del universo, dividida en dos periodos cosmológicos distintos: durante el primero los hombres y el cosmos entero están al cuidado de la divinidad; en el transcurso del segundo período, cuando el dios se desentiende de ellos, surge la necesidad de ciertas regulaciones, entre las que se encuentra el arte de la política, que sirve para suplir la falta del gobierno divino. Se recrea así con acentos cosmogónicos e intención político-propedéutica, al hablar de la primera etapa, una época mítica en que los hombres eran felices y casi perfectos bajo el gobierno del dios. En esta primera etapa, que será especialmente de nuestro interés por la idea tradicional de la edad de oro de eterno retorno, se constatan diversos elementos de la narrativa mítica y del folklore referidos a aquella feliz edad en diversas tradiciones míticas: por ejemplo, el sol realiza un curso inverso al actual, los hombres nacen ancianos y su vida corre hacia la infancia, hay abundancia de recursos, justicia equitativa y buen gobierno, convivencia en paz con los animales, vegetarianismo utópico, etc.

El mito de esta edad de oro bajo el gobierno del dios en el Político recoge claramente el viejo motivo de la tradición literaria y religiosa representada en el mundo griego por las cinco edades de Hesíodo en Trabajos y dias. Para entender la carga filosófica del mito del Político la primera labor indispensable es contextualizarlo en su marco literario, cosa que se ha pasado por alto las más de las veces en la polémica erudita que demuestran muchos de los artículos citados más arriba. La discusión académica acerca de las fases de la historia universal a las que alude el mito platónico y, en concreto, de la raza de hombres que habita en cada revolución del mundo, sus condiciones de vida y su gradación, ha sido 
muy intensa en los últimos decenos. En nuestra opinión, lo más interesante de este debate consiste en examinar la relación con el mito tradicional de la Edad de oro, o edad de Crono en la mitología y la literatura griegas y en constatar en qué sentido y con qué objetivo ha modificado Platón las cinco edades hesiódicas -fruto ya de por sí de una innovación literaria con plena intencionalidad épica, pues, como se verá, en el mito originario son tres (Baldry 1954) - en una estructura de dos o tres fases cósmicas, dependiendo de la teoría que se siga.

En primer lugar, en cuanto a la tripartición de las edades, que transmitía también el aristotélico Dicearco de Mesina en su versión agrícola, y Hesíodo en la religiosa, según los esquemas antiguos que subyacen al mito de las cinco razas humanas de Trabajos y Dias, hay que decir que desempeña obviamente un papel fundamental en el pensamiento político de Platón. La estructura tripartita es, por lo demás, un esquema profundamente arraigado en el pensamiento griego, de raigambre indoeuropea (Dumézil, 1941 y 1999; Alvarado 1993). El filósofo, como es bien sabido, la enmarca en un sistema más ambicioso que incluye una definición del alma humana y del estado ideal. El reflejo de la antigua tripartición de las razas, con sus nombres de metal en gradación preciosa -oro, plata y bronce- se deja sentir en la República en cuanto a los tipos de alma y sus funciones (III 414a-415d) y también en cuanto a las constituciones, cuando se encarga a los gobernantes, combinando estos metales, "aquilatar las razas hesiodeas" (VIII 547a-b) y tender hacia "la antigua constitución", es decir, "un término medio entre la aristocracia y la oligarquía" (547 c) ${ }^{2}$. Las cinco razas simplificadas en tres grupos han perdurado también en los tres tipos de gobierno de las ciudades en el Político (291d), y, en general, en las funciones del alma, las del individuo en sociedad y las virtudes, conformando un conocido ciclo de decadencia y retorno que, en este diálogo hay que armonizar con una doble revolución del universo ${ }^{3}$.

En segundo lugar, es interesante constatar cómo Platón, que conoce bien el mito y lo usa en diversas ocasiones, lo simplifica aquí cosmológicamente en dos edades, una dirigida por la divinidad y otra en la que la humanidad está sola. A este respecto, se ha discutido mucho en los trabajos citados al principio sobre si

\footnotetext{
${ }^{2}$ Para la traducción, cf. J. M. Pabón y M. Fernández Galiano (eds.), 1993.

${ }^{3}$ Los tres tipos del alma, racional (to logistikon), irascible (to thymoeides) y concupiscente (to epithymetikon), corresponden en la República, como es sabido, a las tres virtudes, sabiduría, valor y templanza. La edad de oro se puede asimilar a la monarquía, la timocracia a la de plata, la oligarquía a la de bronce, la democracia es la edad heroica y la tiranía sería una suerte de edad del hierro. Es interesante reparar en las consecuencias políticas de la trifuncionalidad indoeuropea en occidente como hace J. Alvarado, 1993.
} 
hay dos o tres períodos cósmicos en el mito del Político. La interpretación más tradicional hace corresponder las dos revoluciones del mundo a dos etapas de la historia, pese a que algunos autores hablan de tres épocas (Brisson 1995; Rowe 2002) para conciliarlo con la tradición mítica de las tres edades y tres razas de hombres de la literatura universal y el citado Leitmotiv indoeuropeo. Se propone en esta interpretación que durante la primera época, la de Crono, el sol marcha en la misma dirección que durante la actual, la de Zeus. Habría, además, una etapa intermedia de reversión del universo: pero es difícil de justificar sobre la base del texto del diálogo y en la consideración del gobernante divino, por lo que una teoría de tres etapas parece forzar en demasía la lectura de estos pasajes (Horn 2002; Lisi 2004).

En efecto, el mito describe claramente la vida en nuestro universo como resultante de dos revoluciones opuestas de un mismo ciclo: no es tan dependiente en esta parte de Hesíodo como de una visión cosmológica que aun no está del todo clara. La disputada cuestión de si se trata de dos o de tres ciclos (interpretaciones que podríamos llamar tradicional y reciente, respectivamente) ${ }^{4}$, ha vuelto a la palestra en la más reciente contribución de El Murr (2014, 143-188, en esp. 150), que viene a incidir de nuevo en la interpretación tradicional, que habla de la existencia de dos ciclos cósmicos, en vez de tres. El mito del Político se comparó desde antiguo con otras tradiciones cosmológicas: por un lado, los dos ciclos parecieron a algunos una reminiscencia del Zoroastrismo ${ }^{5}$ mientras que, por otro, las tres fases recordaban a la cosmogonía del Timeo (Rowe, 2002), con la que tiene puntos de contacto el mito del Político (p.e. Robinson, 1967). En esta comparación reside otra de las dificultades de la interpretación cosmológica, es decir, en su armonización con lo que escribe Platón en el Timeo. En el caso del Político el mundo gira en sentidos contrarios, dependiendo de si el dios lo dirige o no, mientras que en la cosmología del Timeo no se encuentra un cambio semejante. Quizá se encuentre aquí implícita la noción de alma del mundo en la razón ordenadora que guía el cosmos en la etapa de gobierno divino (Gaiser, 1968, 206), pero el tema sigue sub iudice. Aunque El Murr (2014, 152 ss.) ha opinado recientemente que la visión cíclica del mito central del Político (268d4-274e1)

\footnotetext{
${ }^{4}$ P.e. cf. L. Brisson, 1995 y $1998^{3}$, y C. Rowe, 1999, xx-xxi. Este último autor interpreta incluso la revolución del mundo como algo de un solo sentido: "the reader of the following translation should be forewarned that the rendering of the myth is base on a non-standard reading [...] According to the view reflected in the present volumen, by contrast, things go in the same direction in both the age of Cronos and the age of Zeus, with a relatively short period of reversal taking place on between them."

${ }^{5}$ Según un antiguo trabajo de Goodrich, 1906.
} 
se opone a la del Timeo (41a7-b6), como apunta Lisi (2015) en su recensión de este libro, en este diálogo "se habla también de ciclos históricos que son complementarios al proceso de destrucción que se menciona en el mito del Político" y por ende "no son contradictorias ambas visiones, sino complementarias".

En todo caso, en el Político, dentro del movimiento circular que caracteriza

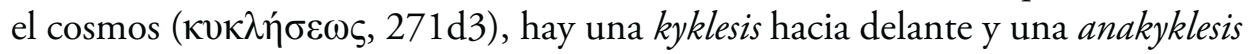
hacia atrás (269e, $\dot{\alpha} v \varepsilon \lambda \hat{i} \xi \varepsilon 1,270 \mathrm{~d} 3)$, conceptos no iguales, pero sí semejantes al Timeo (34a), donde el movimiento del cosmos también es "en círculo", en el característico movimiento circular que en Platón define al cosmos, al alma e incluso al razonamiento (Leyes $897 \mathrm{c}$ ). En el Político la primera revolución, hacia delante o kyklesis, se da cuando la divinidad asiste al mundo y lo guía con su sapiencia sobrenatural desde su torre de vigía (272e). En la fase de gobierno divino vive la raza de hombres áureos, los autóctonos, que, como en Hesíodo, no mueren realmente: "surgiendo de la tierra, en efecto, todos recobraban vida, sin guardar recuerdo alguno de su anterior existencia." ${ }^{6}$ En esta primera etapa, el sol salía por poniente y los hombres nacían ancianos, rejuveneciendo gradualmente hasta desaparecer. Pero hay otra revolución en la que el mundo marcha hacia atrás o anakyklesis, cuando la divinidad está lejos de su gobierno y deja que gire por sí mismo. Esa es la etapa actual, nos viene a decir el mito, con el firmamento en el ciclo que conocemos y la vida humana transcurriendo desde la nińez a la edad anciana. Al final de cada ciclo, sin embargo, se producen grandes conmociones que no parecen constituir una etapa diferenciada, sino simplemente la transición entre las dos revoluciones. De la confusión con estas etapas de transición con una etapa propia se ha podido generar tal vez parte del debate académico antes mencionado.

A nuestro entender no ha de haber necesariamente contradicción entre la tripartición tradicional y la doble y opuesta circunvolución del universo en el Político, como ha sido puesto de manifiesto a la hora de intentar armonizar este pasaje con la cosmogonía del Timeo. Y ello gracias a los cataclismos relacionados con estas dos revoluciones y que ponen fin a las estirpes humanas, como en la tradición del mito. La última aparente y disputada contradicción del mito es que en otras versiones platónicas sobre la historia de la humanidad se ve una cierta continuidad del género humano, mientras que en el mito del Político hay una discontinuidad: esta peculiaridad podría ser explicada tanto por la herencia "discontinua" de las edades hesiódicas como por el recurso a la metáfora mítica

${ }^{6}$ Cito traducciones de Ma I. Santa Cruz, 1988, 527 y 534. También en la página siguiente. 
del fin de una edad y la renovación del género humano. El esquema del mito del Político, en efecto, seguirá ahí de cerca el modelo hesiódico en el sentido de la renovación de los hombres antiguos a través de la desaparición de las razas y el surgimiento a partir de ellas de ciertos daimones tutelares. Veamos qué dice el mito (272e ss.):

"Una vez, pues, que el tiempo de todas estas condiciones tocó a su fin, que debía producirse un cambio y que había desaparecido ya por completo esa raza nacida de la tierra [...] el piloto del universo, abandonando por así decirlo la caña del timón, se retiró a su puesto de observación e hicieron dar marcha atrás al curso del mundo el destino y su inclinación natural".

Resulta difícil no asociar a este piloto con Crono, y su puesto de observación

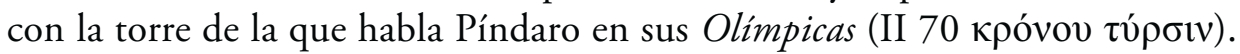
Sigue Platón:

"En ese momento, todos los dioses que, cada uno en su región, asistían en su gobierno a la máxima divinidad, al advertir lo que estaba sucediendo, abandonaron, a su vez, las partes del mundo a las que dispensaban sus cuidados personales. Y éste en su rotar hacia atrás, al sufrir el choque de los impulsos contrarios del movimiento que comenzaba del que acababa, produjo en sí una gran sacudida, cuya consecuencia fue, otra vez, una nueva destrucción de todas las criaturas vivientes.”

Ese fin de raza siempre está marcado en Hesíodo, como veremos más en detalle, por la muerte y paso al más allá de los miembros de cada edad humana en una catástrofe cósmica. Lo que aquí está haciendo Platón es afinar el reloj de la historia universal, o de la primitiva antropología histórica, para hacer coincidir cada cambio de raza hesiódico y cada ciclo que acaba en cataclismo con el extremo de la revolución giratoria del mundo.

Recapitulando ahora, el mito de las edades en Platón señala con claridad la existencia de dos edades del mundo (con sus respectivas épocas de transición), la dirigida por la divinidad y la automática, con dos razas de hombres, una felizmente despreocupada de la política y otra que debe ocuparse filosóficamente de ella. Esta adaptación no se opone a las ideas tradicionales que aparecen en Hesíodo, lo que se puede constatar comparando esta amalgama platónica de tres componentes míticos (la revolución inversa del cosmos, la edad de oro y la generación humana desde la tierra) con la tradición del mito. 
El Murr (2010) ha ensayado una interesante comparación con Hesíodo, situando el mito en su contexto de la tradición mitológica griega. Pero a menudo se olvida que, además de Hesíodo, hay otros muchos testimonios del gobierno divino durante la edad de oro: desde otros mitos como los de Crono, Atreo y Tiestes, hasta los referentes a los misterios órfico-dionisíacos. A nuestro ver Platón refunde en el mito del Politico tres viejos relatos tradicionales: el de Atreo y Tiestes (cf. el resumen que ofrece Apolodoro, Ep. III 10-14), con el Leitmotiv del curso revertido del cielo; el del reinado de Cronos en la edad de Oro; y el de la generación espontánea, a partir de la tierra, de los seres humanos ${ }^{7}$. El propio extranjero, como un buen narrador de mitos, enumera al principio los temas que

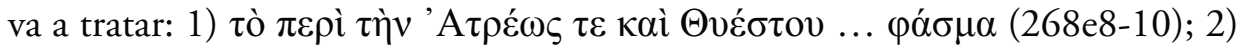

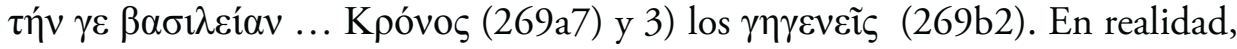
los dos últimos son parte de esa misma idea religiosa de edad de oro a la que

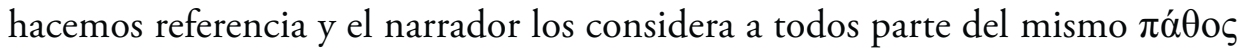

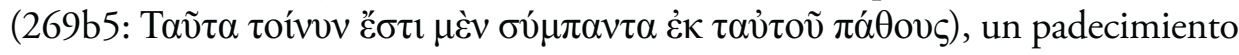
o evento que le sucede a nuestro mundo y a toda la humanidad, de antańo u hogaño. A continuación, el Extranjero de Elea entrará en detalle y desarrolla cada tema por separado y cambiando el orden: 1) en $269 \mathrm{~d}-270$ e, a continuación 3) en $271 \mathrm{a}-\mathrm{c}$ y 2 ) en $271 \mathrm{~d}-272 \mathrm{~b}$, terminando por explicar el cambio entre uno y otro ciclo en $272 \mathrm{~d}-274 \mathrm{~b}$.

La causa de estas modulaciones narrativas, de la combinación de relatos míticos y, sobre todo, la simplificación de las edades en un esquema bipartito ha de deberse sin lugar a dudas a razones de filosofía política, como veremos, pues es aquí, en esta edad llamémosle de hierro, donde sobreviene la necesidad de ocuparse de la techne politike. Para un buen éxito de las cosas humanas en esta nuestra edad del desgobierno por parte divina, una filosofía política inspirada en la divinidad deberá regir a través de su mímesis. Aquí es donde hay que alegar, a modo de comparación, las alusiones al gobierno áureo y divino en las Leyes que se tratarán al final. Por ello esta propuesta se pretende, a continuación, examinar la tradición religiosa y literaria, dando cuenta de su contexto global y no solo circunscrito a Hesíodo, y, en un segundo momento, comparar el trasfondo de su filosofía política con el de las Leyes y sus alusiones a la edad de oro y al gobierno divino, en la creencia de que proporcionan el mejor paradigma interpretativo para entender el mito del Político.

${ }^{7}$ Cf. C. Castoriadis, 2004, 113. Este mito sería la primera digresión en el plan de la obra, pues recordemos que este autor subdivide el diálogo en dos definiciones, ocho incidentes y tres digresiones. 


\section{El mito de la edad de oro: de la religión a la política}

Desde antiguo, la edad de oro llegó a ser un tópico religioso y literario, casi un estado mental, una evasión del espíritu que evocaba aquel ámbito remoto -en el tiempo o en el espacio- en que los hombres vivían sin temor a la muerte, entre abundancia de alimentos y placeres, justicia igualitaria y eterna juventud ${ }^{8}$. Ya en Homero se menciona el prestigioso illud tempus en que una raza de hombres mejores que los actuales convivía con los dioses 9 . Pero el mito de la raza de oro, recurrente en varias culturas, y de origen oriental ${ }^{10}$, entró en el pensamiento religioso griego en época arcaica con el poeta Hesíodo, que representa la base de la tradición mítica griega a este respecto y también, obviamente, para el mito platónico. En Trabajos y días (106-201) el mito de las edades, que propiamente se debe llamar "de las razas" (Baldry, 1952, 89), se relaciona con la propia creación de la humanidad en sus distintas etapas, en tiempos de Crono y los Titanes. En Hesíodo las distintas edades representan nuevas creaciones de seres humanos sin continuidad y sin que, aparentemente, tengan relación unas con otras, por lo que no se puede hablar de una "humanidad" homogénea. Sin embargo, cada raza desaparecida pasará a ocupar en el inframundo (o en el mundo paralelo de lo divino) un estatus de semidioses tutelares de los hombres. El mito se estructura, al igual que el platónico, en categorías según la cercanía a lo divino. La primera y mejor raza es de oro, "en tiempos de Crono, cuando aún reinaba en el cielo"11,

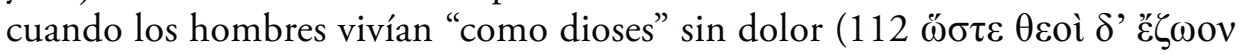

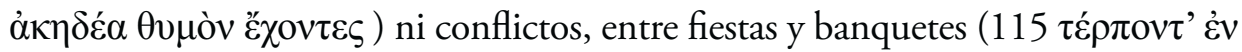
$\theta \alpha \lambda i n \sigma ı)$ espontáneos de la tierra fecunda (117-118), eternamente jóvenes, hasta que, a la hora de morir, cayeron en un dulce sueño, convirtiéndose en genios

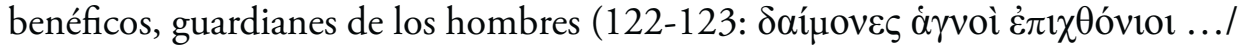

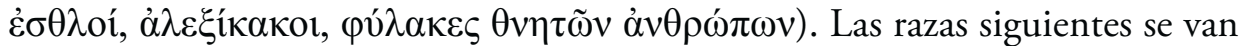
alejando progresivamente del estatus semidivino en una cierta decadencia: los

\footnotetext{
${ }^{8}$ Para un panorama general de la edad de oro, cf. H.C. Baldry, 1952 y H.F. Bauzá, 1993. Para una primera formulación de lo que sigue, cf. Hernández de la Fuente 2009.

${ }^{9}$ Cf. Homero, Il. I, 251-272. Este pasaje hace referencia al prestigio de tiempos pasados con varones sobrenaturales, como VII 120-160 con las evocaciones de Néstor. Para el origen de esta idea antes de Hesíodo, J.G. Griffiths, 1958, 91 y ss.

${ }^{10}$ Sólo hay que comparar las versiones de una edad de oro en el Génesis, en la antigua Mesopotamia o textos de la antigua India como la Bhagavad-Gita. A. Neyton, 1984 da un panorama muy completo, tratando, por ejemplo, el poema sumerio de Enki y Ninhursag (p. 14).

${ }^{11}$ Trab. y dias 109-111. Cf. P. Mazon (1951) 90 ss.
} 


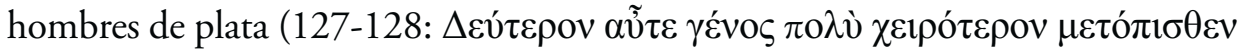

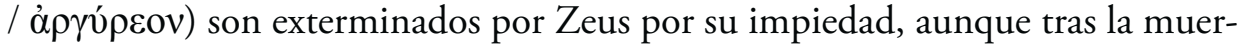

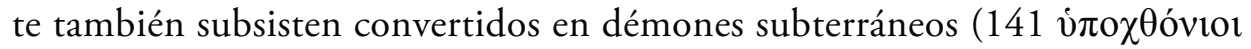
$\mu \alpha ́ \kappa \alpha \rho \varepsilon \varsigma)$; la raza de bronce, nacida de los fresnos, es aniquilada por sus propias

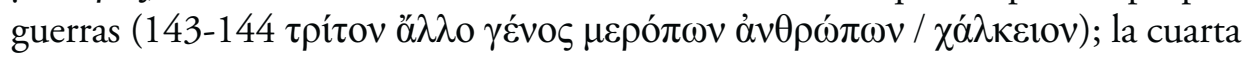

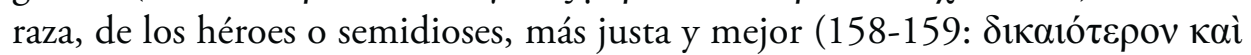

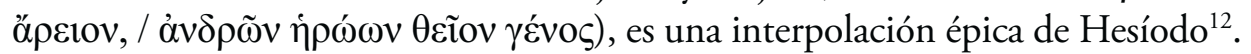
Esta raza acabará sus días combatiendo en torno a Tebas y Troya, y en el más allá habitará las islas de los Bienaventurados ${ }^{13}$, regidas por Crono, según reza una interpolación órfica en Hesíodo ${ }^{14}$. Por último, la quinta raza, es la de hierro (176

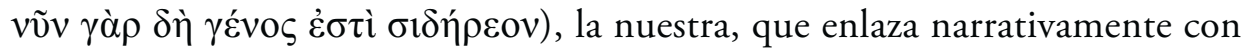
el mito de Pandora, y en la que, ya lejos de las características semidivinas de la edad de oro, reinan la guerra, la muerte, la injusticia y la enfermedad. Hesíodo manifiesta su deseo de no vivir en esta edad de hierro, sino de haber "muerto antes o haber nacido más tarde" (175), lo que sugiere la idea de que las razas humanas se suceden en este orden en un tiempo circular universal y que la edad de oro habrá de volver. Tal es la base de su prestigio, primero religioso y luego político: el eterno retorno de un esquema de gobierno y convivencia utópicos.

En efecto, la raza de oro o "tiempo de Crono" pasó pronto a ser una expresión proverbial para designar este paraíso de abundancia, y las diferentes edades, no ya las cinco que enunciara Hesíodo, sino más bien agrupadas y resumidas en tres, pasaron al pensamiento griego en una estructura tripartita que, como se ha dicho, estaba bien arraigada en él. El oro y la plata son la juventud y el vigor, el bronce y la edad de los héroes la vida adulta y la edad de hierro la vejez ${ }^{15}$. Se

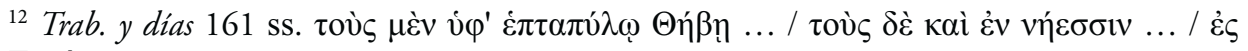
Tpoínv...

"Esta generación se sale claramente del marco del mito [...] La explicación es sencilla. Hesíodo no podía ignorar la edad homérica”, cf. H. Fränkel, 1993, 125-6.

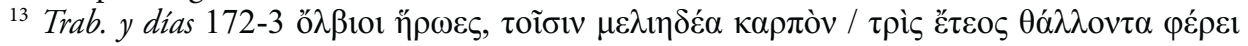

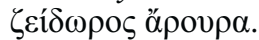

${ }^{14}$ Se trata a todas luces de una trasposición de los tiempos de Cronos - de la edad de oro- a la tierra, con las mismas características de la edad dorada: los héroes son también felices y viven en una utopía de gran abundancia.

${ }^{15}$ Puede compararse esta estructura con las tres funciones indoeuropeas que proponía G. Dumézil, válidas para dioses y hombres, y también para las edades, en sus ya añejos pero fundamentales estudios sobre la historia de las religiones indoeuropeas, cf. G. Dumézil, 1941 y 1999: se trata de la función de administración de lo sagrado, la función del poder (físico, político) y la función productiva (la agricultura, la fecundidad). Para la gran influencia de estas nociones en el campo del derecho político, cf. J. Alvarado 1993.
} 
afianzó también la idea de su retorno cíclico, que se corresponde con la propia concepción del tiempo entre los griegos (Vidal-Naquet, 1983, 61), como se ve tanto en Hesíodo (Trabajos y Días 175) como en la reestructuración platónica del mito del Político (269d-e). Aquel tiempo pasado de justicia y abundancia volverá, y de hecho pervive en el presente al estar localizado ora en un lugar geográfico impreciso y lejano, donde sigue inalterable (las Islas de los Bienaventurados o la primitiva Italia donde Virgilio situaba el reino de Saturno), ora en un más allá paradisíaco y prometido (los Campos Elíseos, etc.). Crono, así, no sólo reina en la utopía pasada, sino también en la del más allá, en una prolongación de la utopía en un contexto geográfico fantástico (Neyton, 1984, 61 y ss.), una idea de gran fortuna en la literatura griega de viajes ${ }^{16}$. Pero, en cierto modo, también pervive la edad de oro gracias a la religión: por un lado, según las tradiciones órficas recogidas por Píndaro ( $\mathrm{Ol}$. II 68 ss.), después de ser destronado por Zeus, Crono tuvo un dorado exilio en este paraíso donde las almas de los iniciados que "permaneciendo hasta tres veces a uno y otro lado, se atrevieron a mantener su alma lejos de toda injusticia, recorren el camino de Zeus hasta llegar a la torre de Crono ${ }^{17}$. Y allí las brisas oceánicas abrazan la Isla de los Bienaventurados" ( $\mu \alpha \kappa \alpha ́ \rho \omega v v \tilde{\alpha} \sigma o v)$.

Para el orfismo, que impregna decisivamente la escatología platónica, el mito de las edades tiene una enorme importancia. Los órficos afirmaban que existieron tres razas de hombres, de oro, de plata y de bronce ${ }^{18}$. Y hay un interesante mito órfico sobre la generación de la raza humana actual, la de hierro, que refiere que se formó a partir de las cenizas de los Titanes, fulminados por Zeus tras haber consumido a Dioniso Zagreo ${ }^{19}$. Estos Titanes se parecen mucho a aquellos

${ }^{16}$ Eliano (Varia historia III 18) transmite un fragmento del platónico Teopompo sobre la

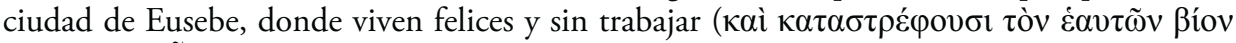

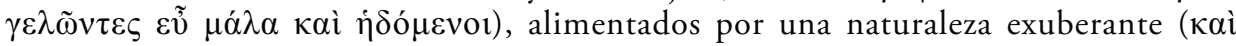

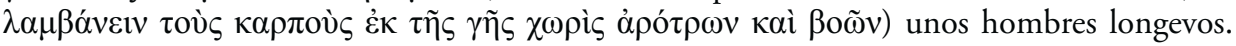
Otros ejemplos en el mundo lunar de Luciano (Historias verdaderas II) o el excelente país de los etíopes en Heródoto (III 17 ss.).

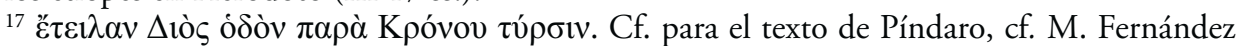
Galiano (ed.), 1992148.

${ }^{18}$ Según, por ejemplo, testimonio de Proclo, In Remp. 2, p. 74 Kroll. La fecha tardía de los testimonios no impide traer a colación este pasaje como puramente órfico, cf. L. Brisson, 1987.

${ }^{19}$ La historia se encuentra en Calímaco fr.643, Euforión fr.13, Plutarco, De esu carnium, 1.996, Proclo, in Pl. Tim. 35, Olimpiodoro, in Pl. Phaed 61 y 108 Nono, Dion. VI 165 ss., etc. Cf. en general la edición de los fragmentos órficos de A. Bernabé en Teubner. En todo caso el mito de Dioniso no se narra de la misma manera en Olimpiodoro y en Proclo, habiendo matices interesantes para el orfismo, cf. L. Brisson, 1992. 
démones que en Hesíodo resultan de los hombres de la raza plata hesiódicos, malvados y benefactores a la par, que según este mito órfico resultan ser también origen de la actual raza humana. Por otro lado, pero relacionados con el orfismo, están los ritos de Dioniso, dios de la utopía áurea en la tierra (J.-P. Brisson, 1988, 930, Hernández de la Fuente, 2009).

El tema de la edad de oro como utopía religiosa tendrá así pronto derivaciones para la política: el relato platónico del Político remite a una edad en la que "no existía entre los hombres guerra ni disensión" y por tanto no necesitaban constituciones. En ella, los medios de vida eran compartidos y "espontáneos"

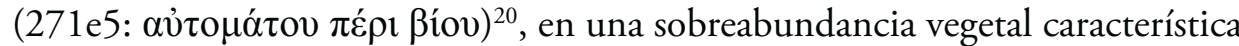
de la utopía religiosa del mundo dionisíaco, con "frutos abundantes" (272a3:

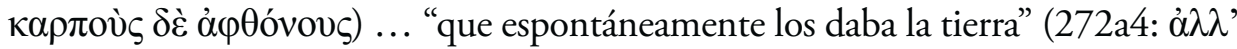

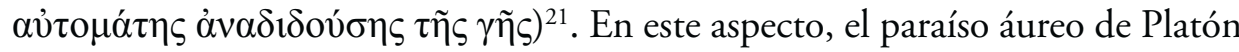
presenta también una abundancia vegetal, como en otros testimonios ya citados del mito. Esta edad de abundancia y justicia, sin derramamiento de sangre y con exuberancia vegetal, se relaciona también con el vegetarianismo utópico -de raigambre órfico-pitagórica-: como se trataba en una obra perdida de Dicearco de Mesina sobre la edad de oro y los primeros seres humanos, que conocemos gracias al De abstinentia de Porfirio (IV $21 \mathrm{ss})^{22}$. La antigua raza humana vivía cerca de los dioses pues su dieta era perfecta e incruenta, lo que era el origen de su justicia y buen gobierno ${ }^{23}$.

\footnotetext{
${ }^{20}$ Político 271e-272b. Cito la traducción de A. González Laso (ed.) 1994, 27.

${ }^{21}$ Seguimos la edición de E.A. Duke et al.,1993, 499, que prefiere la lectura de las familias

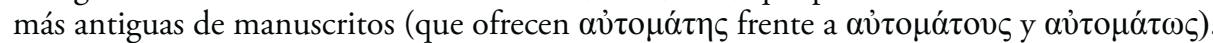

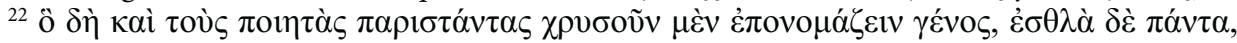

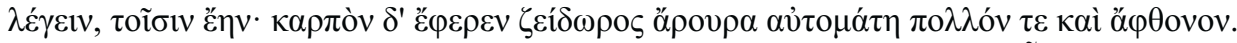

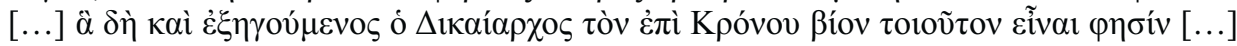

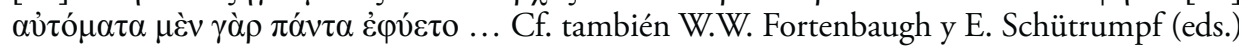
2001, n.56B: "Dicearco [...] dice que bajo Saturno, es decir, en la edad de oro, cuando la tierra proveía de todas las cosas, nadie comía carne, sino que todos vivían de frutas y verduras que nacían espontáneamente de la tierra.” Las traducciones al castellano de otras lenguas, cuando no se especifica lo contrario, son nuestras.

23 "Esto es lo dicho por Dicearco, cuando narra las antigüedades de los griegos y relata como bendita la vida de los humanos primeros, a la que contribuía en no menor medida que otras cosas la abstinencia de comida animal. Así, no había guerra, y la injusticia había sido expulsada. Pero luego, junto con la injusticia hacia los animales, vino la guerra y la competencia de unos contra otros; por ello me atrevo a decir que la abstinencia de los animales es la madre de la justicia, puesto que la investigación y la experiencia revelan que el lujo, la guerra y la injusticia vinieron juntamente con este derramamiento de sangre." Cf. W.W. Fortenbaugh y E. Schütrumpf (eds.) 2001, n.56A.
} 
Por otra parte, la edad de oro, como utopía de abundancia, tendrá una clara relevancia en la actualidad política de la época de la guerra del Peloponeso en Atenas, como puede verse en la llamada "Comedia utópica" 24 , que evoca aquellos tiempos felices en medio de las dificultades del presente ${ }^{25}$. A finales del siglo $\mathrm{V}$ a.C., la idea de la edad de oro aparecerá cada vez más frecuentemente en el imaginario griego, también con un significado hondamente político. La comedia de Eupolis La raza de oro, por ejemplo, era una sátira política contra Cleón que hacía referencia a la igualdad democrática de la edad de Crono (fr. 291

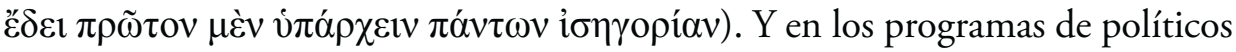
atenienses de los más diversos signos, desde Cimón a Pericles, habrá abundantes referencias a la vuelta a esa edad de oro añorada ${ }^{26}$. El debate de la edad de oro, en fin, estaba muy vivo en lo político, tras haber obrado el salto desde lo religioso a la actualidad y a las propuestas utópicas. En palabras de Vidal-Naquet, "la edad de Cronos, 'la vida en la época de Cronos', como se decía, es un eslogan para sectas filosóficas y religiosas que no están satisfechas, o ya no lo estaban más, con el orden cívico existente." (Vidal-Naquet, 1978, 134) Sin duda, había mucho de transgresión o subversión de la ley y el orden en la edad de oro: frente a la religión cívica, en el caso de los misterios, y frente a la ciudad-estado, en el caso de la utopía política. Prueba de ello es que tiempo después los cínicos hicieron de la "libertad de los tiempos de Crono" un lema y un ideal de su modo de vida y pensamiento en la época de crisis de la polis ${ }^{27}$.

De esta variada tradición como antecedente, que hemos resumido a muy grandes rasgos, se toma la forma literaria del mito del Politico de Platón, quien la reflejó en otras obras siguiendo la evolución de su pensamiento, fundamentalmente en las Leyes (p.e. 676b y 713b), como se verá en el siguiente epígrafe de esta contribución. A la hora de extraer las razones que llevan a Platón a incluirla

${ }^{24}$ Como refiere críticamente A. Lesky, 1969, 452. Para algunas de estas utopías griegas, cf. L. Bertelli, 1973.

${ }^{25}$ Cratino (Ateneo, Deipn. VI 267e) en Ricos, Crates en Los animales, Teleclides en Anfictiones, etc. Aristófanes, por su parte, no deja de evocar esa edad mítica entre temas también órficos y dionisíacos, como se ve en la katábasis de Dioniso en Ranas o en la parodia cosmogónica de Aves (698 ss.).

${ }^{26}$ Cf. p.e., Plutarco, Cim. X 7. Era un tópico antiguo. Según Aristóteles, Cons. At. XVI 7, también la política del tirano Pisístrato se había equiparado a la vida en tiempos de Crono.

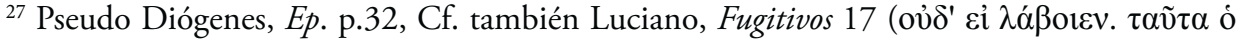

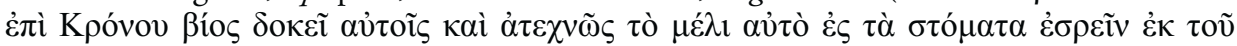
oủpavoṽ). Por otro lado, Antístenes (fr. 189 G.) defiendía la estirpe de los Cíclopes como pertenecientes a esa edad de oro, ya que gozaban tambien los frutos "espontáneos" de la tierra. 
en su discusión filosófica sobre el mejor gobernante, no hay que olvidar, como han hecho algunas de las interpretaciones tradicionales, el contexto histórico de la crisis de la democracia ateniense y el auge de las utopías escapistas basadas en la noción de la edad de oro. El recurso a este tema mítico en la obra política de Platón confirma en cierto modo la gran popularidad de este "dorado primitivismo", aunque habrá que notar una cierta distancia crítica con respecto a la subversión que, en la época de la Guerra del Peloponeso, había significado este motivo, como suele ocurrir en la actitud del filósofo a la hora de acercarse a la tradición de los mitos ${ }^{28}$.

Quizá un buen apunte de ello sea el pasaje en que el Extranjero de Elea pregunta si las criaturas de la edad de Crono vivían una vida más feliz que las de la edad de Zeus (272 b), a lo que se responde de forma un tanto ambigua ${ }^{29}$. Vistas las penalidades de la política en la democracia ateniense durante y después de la guerra, tras sus derrocamientos oligárquicos de 411 y 404, y los numerosos procesos políticos y persecuciones, la cuestión es cuando menos curiosa. Se ha hecho de este pasaje un lugar clave para la aplicación político-filosófica del mito (Lisi, 2004), pero no creemos que las ambigüedades que expresa acerca de la felicidad de la vida en aquella edad invaliden en absoluto el discurso general de esta idea áurea como guía del gobierno divino. En especial, y como hemos señalado, hay que reparar en el prestigio que en el pensamiento tradicional tenía la idea del regreso cíclico de las edades, que permite pensar en la esperanza de que regrese el momento del gobierno divino. Si ya en los Trabajos y días hesiódicos (175) se aludía al eterno regreso de la edad de oro en un tiempo circular universal, mucho de ese prestigio del retorno quedará en las alusiones al mito en el Político (269d-e): después de la edad actual volverá esa edad en que los hombres rejuvenecen desde la vejez y viven en un paraíso alimenticio y de justicia, gracias a ese vaivén del mundo, que no es sino un movimiento circular $(\text { kyklesis })^{30}$. El universo marcha guiado por la divinidad o en solitario, en cuyo caso hace una vuelta cíclica -"y esa su marcha retrógrada se da en él necesariamente como algo

\footnotetext{
${ }^{28}$ Por ejemplo, en las Leyes a veces recomienda el vino y otras limita y proscribe su uso, como veremos. Es una ambivalencia que ha notado P. Vidal-Naquet, 1978, 141: "Platón resistió hasta el fin los diferentes espejismos de la edad de oro [...], pero no había falta de tensión en ellos."

${ }^{29}$ Dependerá de si tales hombres se dedicaban a la filosofía o si, por el contrario, "atiborrándose de alimentos y bebidas hasta saciarse, conversaban entre sí y con los animales sobre mitos como los que ahora se cuentan a propósito de ellos" (según la traducción de A. González Laso, 1994, 28).

${ }^{30} \mathrm{Tal}$ y como entienden el pasaje C. Robin y P. Vidal-Naquet, 1978, 138.
} 
que le es connatural"- , con los grandes cataclismos de transición para los hombres de ambas edades. Ello parece, a todas luces, una variación racionalizada del mito tradicional y adaptada a las ideas platónicas sobre el movimiento circular del cosmos y del alma ${ }^{31}$, expresada en un momento político crucial, tras la crisis de la democracia ateniense y en plena explosión de las diversas utopías que evoca la comedia u obras como el Busiris de Isócrates.

\section{La edad de oro en las Leyes}

En el camino del pensamiento platónico, inserto en esta vuelta de siglo tras la guerra del Peloponeso y el tira y afloja entre democracia y oligarquía, las obras tradicionalmente llamadas "de madurez", y sobre todo las Leyes, dejan ver en nuestra opinión la importancia que el filósofo concedió a la edad de oro en la concepción mítico-religiosa del poder y de la ley. Si se repasan las alusiones a este Leitmotiv en el último proyecto político de Platón para la ciudad cretense de Magnesia se pueden trazar ciertos paralelos con el mito del Político que son especialmente interesantes para comprender su misión no sólo en ambos diálogos, sino en el marco global de la política platónica. El tópico mítico de la edad de Crono encuentra un desarrollo en las Leyes que recoge la idea del gobierno divino del cosmos esbozada en el Político y, más allá de sus concepciones cosmológicas, trata de tender puentes con las ideas religiosas de lo que Gilbert Murray llamaría "el conglomerado heredado", en este caso de la religión cívica y también de la órfico-dionisíaca. En general se ha hecho notar en varias ocasiones, y así lo hemos defendido en otros lugares, que el filósofo ateniense incorpora y adapta a su último proyecto de politeia ideal diversas ideas clave y herramientas de la religión tradicional, tales como los oráculos, las purificaciones, o el culto a los héroes, Apolo, las Musas y Dioniso. También la noción de una edad dorada en la que el mundo estaba bajo el gobierno divino es aludida en varias ocasiones en las Leyes: la aspiración del político platónico en este mundo, como veremos, habrá de ser conseguir una mímesis lo más cercana posible a aquel gobierno divino que evoca el mito.

\footnotetext{
${ }^{31}$ En palabras de J.-P. Vernant, 2001, 25-26, "las edades se suceden para formar un ciclo completo que, acabado, recomienza, sea en el mismo orden, sea más bien como en el mito platónico del Político". Sobre el movimiento circular que es característico del cosmos y del alma, cf. Fedón 111e-112e, Fedro 247 b-d, República 616b-617d y Timeo 34a-b.
} 
En primer lugar, cabe destacar la concepción de las leyes, y del propio proceso de la legislación y sus actores, como perteneciente al ámbito de lo divino. Así se ve en 624 a y siguientes, cuando se introducen los exempla de las legislaciones míticas de Creta y Esparta, en el libro I de las Leyes, que proceden respectivamente de Zeus y Apolo por mediación de los semidivinos legisladores Minos y Licurgo. Al no poderse regir el mundo directamente por la guía de lo divino, en esta etapa de gobierno humano o "edad de hierro", se diría que hay un recurso consciente de imitación de ese mundo por medio de ciertos legisladores mánticos asimilados a figuras heroicas y semidivinas, con los que se empieza la indagación en la ley. Pero, por otro lado, la legislación humana es designada con diversas metáforas a lo largo de las Leyes que son muy relevantes porque apuntan a un tipo de percepción suprarracional -sea poética, profética o mítica- y aluden a un contacto privilegiado con lo sobrenatural: muy significativamente la legislación es comprendida como "la mejor tragedia" ( 817 b) y, sobre todo, un "juego" (769a, 685a, 712b), de una forma que recuerda al nivel alusivo al mito que se mencionaba en el epígrafe segundo.

Pero si hay un pasaje que a nuestro juicio continua, y en cierto modo ilumina, el mito del Político en el plan platónico de fundamentación mítica del poder es el libro IV de las Leyes, donde se dan ciertas claves de hacia dónde se ha de dirigir la figura del político y el legislador a cuenta, de nuevo, del mito de la edad de oro. Dice el pasaje en cuestión, que extractamos convenientemente:

"La tradición nos ha transmitido una leyenda de la vida feliz de los hombres de aquel entonces, que lo poseía todo en abundancia y de manera espontánea. Se dice que la causa de todo esto era que Cronos, conociendo [...] que el ser humano es incapaz de no llenarse de injusticia, colocó [...] como reyes y gobernantes nuestras ciudades, no a seres humanos, sino seres de una estirpe más divina y

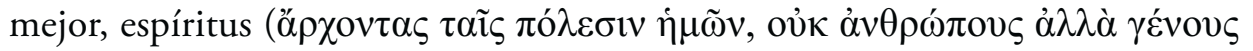

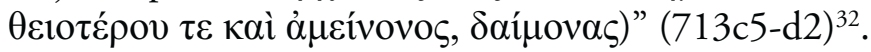

Así, bajo estos espíritus de "raza superior", que recuerdan a los $\delta \alpha i ́ \mu o v \varepsilon \varsigma$

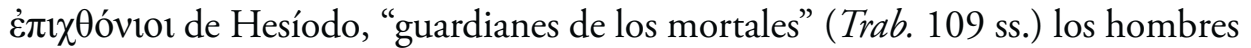
vivían felices. Hoy ya no es así, y nos encontramos, recordando a Hesíodo, en la triste y violenta edad de hierro. En consecuencia, hoy en día lo que habría que hacer para obtener el buen gobierno en nuestra época y en nuestro mundo, dice el texto, no sería sino "imitar por todos los medios la vida llamada de la época

32 Traducción de F. Lisi (ed.), 1999a, 369-370. 
de Cronos"33, sus comunidades políticas (713d-e), que proporcionaron, como en el primer ciclo del Politico, paz, justicia y abundancia. Una mímesis de los modelos utópicos del mito referidos a esa edad legendaria del pasado. Bajo el amparo del gobierno áureo existía en aquella edad una abundancia de justicia

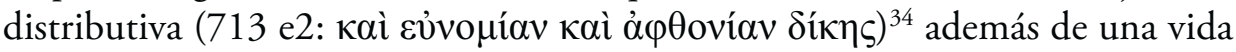
sin trabajo y fatigas ${ }^{35}$. Parece que la política es algo propio de esta nuestra época, que requiere leyes por no estar regida directamente por la divinidad, y no es algo que existiera de la áurea edad de Crono caracterizada por la equidad bajo la guía del dios o de seres divinos.

Se insiste en las Leyes en que la abundancia áurea no solo era alimenticia sino también de justicia y buen gobierno: pero la justicia interna del cuerpo, la dieta alimenticia y la justicia de la comunidad se relacionan. En palabras de Cornelius Castoriadis $(2004,115)$, "esta edad de Cronos es [...] el mito del comunismo primitivo, pero también un periodo de abundancia”. Y no hay que descuidar el aspecto nutritivo y dietético, por la importancia que tenía no solo en la filosofía antigua (piénsese en lo que se cuenta sobre las actitudes de Pitágoras, Platón o Aristóteles acerca de la alimentación), sino también en las prescripciones alimenticias de diversos movimientos religiosos (obvio es el caso de los órficos).

Hay que destacar que, en las Leyes, la justicia de aquella edad concernía tanto al nivel del microcosmos humano, su alimentación, cuanto a la de la convivencia entre seres humanos, y por supuesto también con los animales, en una suerte de armonía cósmica. Cuando se trate el descubrimiento de la agricultura en las Leyes también se aludirá a la alimentación áurea de esa edad mítica "cuando [los hombres] no osaban ni probar el buey y no tenían las divinidades ofrendas de animales, sino mezclas líquidas de harina, miel y aceite, frutos embebidos en miel y otras ofrendas puras semejantes, mientras se apartaban de la carne como si no fuera pío comerla ni manchar los altares de los dioses con sangre, sino que aquellos de nosotros que vivieron entonces llegaron a tener una especie de vida llamada órfica" ${ }^{36}$.

\footnotetext{
33 Traducción de F. Lisi (ed.), 1999a, 370.

${ }^{34}$ Cf. F. Lisi, 1985, 213 ss., para el orden bajo Crono. Hay que llamar la atención sobre el uso de Eunomia, que no ha de ser interpretado como existencia de leyes en aquella edad de gobierno divino (cf. ibid. 230).

${ }^{35}$ Es interesante lo que puede suponer para la labor del filósofo la vida ociosa. Cf. L. Brisson, 2005 y F. Lisi, 2004.

${ }^{36}$ Leyes VI, 782c. Traducción F. Lisi (ed.) 1999a, 493.
} 
Aunque es cierto que este pasaje no cita explícitamente la edad de oro, la alusión a la tradición del vegetarianismo utópico que se mencionaba más arriba es innegable. Aquí se trata de ensalzar aquel tipo de vida justa, anterior en el tiempo, en la edad de oro, de unos ancestros puros que tenían una alimentación "sin derramamiento de sangre" y por tanto acorde con la idea de justicia áurea. Aquí hay que citar el caso posterior de la antropología histórica de Dicearco, que recoge el mito tradicional de las edades con una perspectiva temporal semejante a la platónica y quizá deudora de ella ${ }^{37}$.

Pero este asunto concierne también al alma. No hay que olvidar que la edad áurea no restaura tan sólo la abundancia alimenticia y el igualitarismo político, sino también la abundancia de felicidad y el contacto con lo divino, al menos para los iniciados en las fiestas de los dioses: al hablar de la educación en las Leyes (653 c-e), la música y la danza aparecen como un alivio de las penurias de la actual edad de hierro, una cierta restauración de la edad de oro concedida por los dioses a los hombres, pues, "para que recuperen su estado primigenio, les dieron a las Musas y a Apolo, el guía de las musas, así como a Dioniso, como compañeros de sus festivales" 38 . Y todo ello, esa recuperación del "estado primigenio" del hombre, no son sino juegos (paidian), por usar la terminología del Extranjero de Elea en el Político, que logran revertir, siquiera momentáneamente, el curso de las edades y traer de vuelta la edad de oro a través de la música, el baile, Dioniso, Apolo y las Musas. Esto se ve también en el uso de las festividades relacionadas con divinidades de la tradición y en sus correspondientes coros, tal y como se mencionan en las Leyes: suponen una restauración del tiempo mítico, a través de las fiestas o en los coros como el de Dioniso. El curso de la vida normal también se revierte en la experiencia áurea dionisíaca, como en el mito del Político, y los ancianos marchan hacia una juventud renovada, tal y como ocurría en la revolución del mundo guiada por la divinidad ${ }^{39}$. También en las Leyes se puede constatar esta conexión entre Dioniso y la edad de Crono en el libro II, donde se presentan ciertas reglas para el uso del vino que recuerdan, por un lado, a las

\footnotetext{
${ }^{37}$ Como ha visto T. Saunders, 2001, 242, estudioso de las Leyes de Platón, en cuanto que está articulada "en base a las tres etapas históricas de la alimentación para la raza griega: la edad de oro, cuando los hombres simplemente comian el producto espontáneo de la tierra, sin tener que trabajar por él; la época pastoral, caracterizada por el dominio de los animales y la ingesta de su carne, que tomo como implícita por 'pusieron sus manos sobre ellos' (epsanto) y, la época de la agricultura".

${ }^{38}$ Habla de los estrechos vínculos de Dioniso con la edad de oro M. Detienne, 1977, 200. Para la traducción del pasaje, F. Lisi (ed.), 1999a, 244.

${ }^{39}$ Para el rejuvenecimiento en Eurípides, cf. el estudio de vocabulario de E.M. Thury, 1988.
} 
alusiones dionisíacas al camino del alma de los iniciados en las distintas etapas de los misterios, pero, por otro, a este rejuvenecimiento áureo de los ancianos en el mito del Político y en toda esta tradición del "juego serio" que implica el nivel mítico religioso, en esta ocasión bajo el signo de Dioniso (cf. Hernández de la Fuente, 2013). Así, los ancianos invocarán con preferencia en sus coros a este dios que les devuelve momentáneamente el vigor juvenil, la fuerza áurea: "que [el miembro del coro] convoque a Dioniso al misterio y al mismo tiempo juego de los más ancianos [...] para que rejuvenezcamos" ${ }^{\prime 0}$.

En los párrafos anteriores se ha visto cómo se alude en las Leyes a la noción de la edad de oro, en diversos pasajes que tienen que ver con la exaltación de esa época feliz bajo el gobierno divino, que sigue presente en la edad actual a través de ciertas experiencias religiosas y legislativas. Por último, resta la impresión indeleble de que la idea del mundo perfecto del pasado legendario bajo el gobierno de Crono funciona ante todo como tópico político y modelo para los gobernantes de este mundo, que han de tender a la mímesis del arquetipo divino. Esto se habrá de obrar, a ser posible, en la persona de un "hombre divino", un filósofo gobernante en contacto con lo trascendente. Pero, de no ser posible esto, como es seguro en nuestro mundo alejado de la divinidad, al menos se podrá lograr mediante unos nomoi ("leyes", pero también modos y medidas tradicionales de la música, del arte y de la costumbre) que se inspiren en aquel mundo mítico.

\section{Algunas conclusiones sobre el mito del Político y el gobierno}

La edad de oro, que había centrado durante tanto tiempo el debate social y político en tiempos de crisis para la polis, se perfila para Platón como una metáfora del ideal de gobierno divino también para un mundo futuro. Recientemente, Van Noorden ha estudiado la raigambre hesiódica del mito de las edades en Platón y ha constatado cómo se adapta filosóficamente en cada lugar donde se utiliza, según el nivel alusivo y la voz del narrador del mito en su propedéutica filosófica: la finalidad de llevar al interlocutor, mediante el ejemplo, a la vida filosófica, trasluce en todo momento ${ }^{41}$. Para la política platónica es muy notable, entonces, la reutilización o reconstrucción de la tradición religiosa encarnada por

40 De nuevo, cf. la traducción de F. Lisi (ed.), 1999a, 271.

${ }^{41}$ Van Noorden 2015, Cap. 3, 93 ss. 
el mito de las edades de cara a su plan filosófico. Por ello, se podría decir que, para la ciudad de las Leyes, el modelo en el trasfondo es esa legendaria ciudad de Cronos: con ello se afianza el fundamento mítico-religioso del gobierno que ya está presente en el Político y que alcanzará su mayor concreción en las Leyes.

Por decirlo con palabras de P. Vidal-Naquet "las mejores organizadas entre las ciudades-estado existentes son copias de las formas de autoridad y adminis-

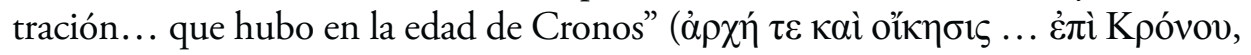
Leyes 713b2, Vidal-Naquet, 1978, 140).

El gobernante ideal, también en el Político, parece transitar así desde las fallidas definiciones de pastor de hombres (y la posterior del político como tejedor) a una definición implícita en algunas expresiones y actitudes del Extranjero de Elea. Como ha visto Montserrat en una reciente contribución, el mito viene a enderezar el iter lógico de la diairesis platónica, en pos de la figura del político, pero no resulta en una clarificación total del camino que se debe seguir: la paradoja es que, pese a poner la edad de Crono como modelo político a imitar, esto debe hacerse con las herramientas de la edad de Zeus y, por ende, también "se puede pensar que la edad afortunada es la nuestra, como resulta evidente por la presencia del logos y de la filosofía" (Montserrat, 2014, 110). Sin embargo, cabe argüir que el mito no pretende, como ya es sabido en su uso platónico, dar soluciones de clara aplicabilidad. El discurso mítico, como hemos pretendido mostrar desde el principio, es clave en ese sentido para entender lo que se plantea como un "juego" (268d9), que revela una paideia divina. A partir de este momento resultará difícil, de hecho, definir a lo largo de la conversación algo que es percibido desde un nivel de conocimiento inexplicable, como un sueño,

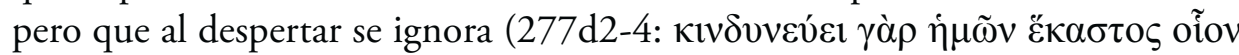

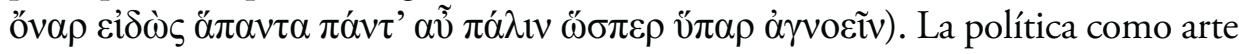
más divina que regia queda así reservada a la esfera de este tipo de conocimientos, propios del pensamiento mítico, como son, aparte de la noción del juego, el sueño y la visión. De hecho, cuando parece que el extranjero va a desvelar ya la naturaleza del político, lo compara con el sacerdote profético (290c4-5: Eỉoì

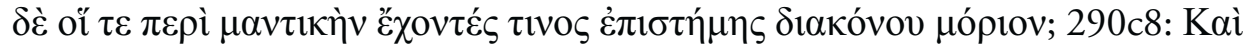

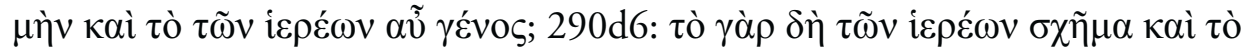

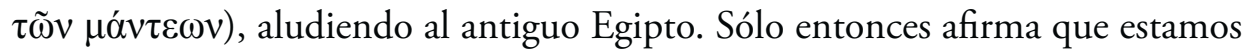

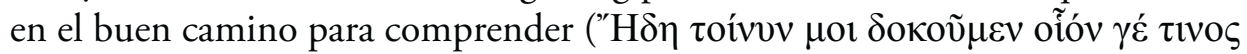

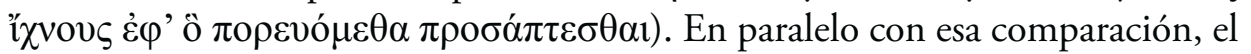
Extranjero Ateniense de las Leyes, tal vez un trasunto del propio Platón, es interpelado en 634e así: "Muy bien hablas, oh extranjero, como si fueras un adivino" 


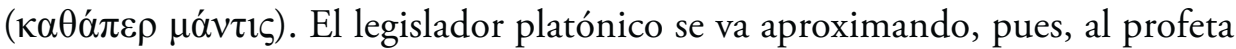
desde el Político a las Leyes.

El fundamento religioso y profundamente tradicional de todo el mito del Político resulta obvio a estas alturas si se repara en esta comparación con el nivel de alusión propio de las visiones, sueños y profecías. Platón recoge la tradición religiosa griega y a la vez innova para trazar nuevos horizontes filosóficos. Los mitos aparecen siempre que el filósofo quiere tratar ciertos asuntos de importancia y necesitados de una especial disposición del alma, y asimismo ocurre con otras alusiones a la religión tradicional, como los oráculos. Siguiendo en este punto a F. Lisi no hay que descuidar, como lo ha hecho en ocasiones la crítica tanto antigua como moderna "el carácter profundamente religioso del pensador ateniense" ni olvidar nunca que en su filosofía "lo divino está siempre presente" (Lisi, 2004, 88 y 89). En definitiva, y en palabras de este autor, "no hay nada en el texto de Platón que lo oponga a la religión de los padres, su filosofía es, más bien, un intento de combinar la religión astral con las creencias politeístas tradicionales." (Lisi, 2004, 73-90, cf. también 88).

Esta combinación de su religión del sumo bien con la tradición religiosa se puede constar especialmente en el mython mythesthai en sus diálogos. El vocabulario religioso, por ejemplo, oracular en el caso del verbo manteuomai, se ha estudiado en ocasiones (Collin 1952) como reconstrucción de un pasado mítico con un sentido metafórico a la hora de expresar teorías más relevantes, cautivar a los interlocutores, oyentes o lectores, o persuadir en un nivel en que el conocimiento se torna ciertamente suprarracional. Así, es un conocimiento ajeno a lo humano y a sus explicaciones el que emplea el recurso de la visión cuando el Joven Sócrates, extrañado ante lo que cuenta el extranjero, le dice que "parece

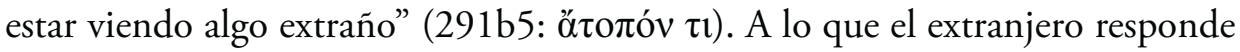

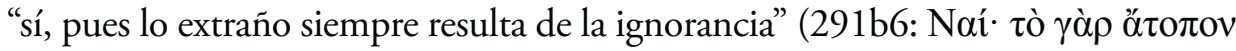

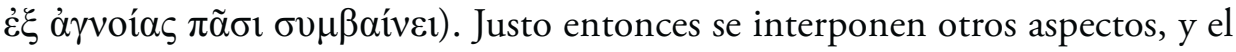
discurso vuelve a su cauce de definiciones, clases y especies, con el discurso de las formas de gobierno.

Habrá que esperar a las Leyes, que comienzan bajo los auspicios de la figura mítica de Minos, legislador y político inspirado por la divinidad, para que el extranjero de Atenas hable "como un profeta" (634e) y consagre una exhaustiva teoría política casi teocrática basada en el respeto a la tradición religiosa más arcaica, siempre fundamentada filosóficamente de forma que armonice con la idea del sumo Bien. En fin, en el mito del Político, el filósofo obrará de manera 
muy semejante a la detallada regulación de la ciudad y sus cultos de las Leyes. El tratamiento de la edad de oro, como se ha examinado desde la tradición míticoreligiosa y literaria, es un buen ejemplo de cómo Platón sistematiza las leyendas y cultos tradicionales para crear su antropología histórica, reuniendo materiales de muy diversa procedencia y con una finalidad político-propedéutica muy evidente como programa en su proyecto de reforma de la ciudad estado. La mejor ciudad será la más parecida a la ciudad de Cronos, en la mítica edad de oro. Y en esta nuestra edad, nos vienen a decir tanto el Extranjero de Elea como el de Atenas en su registro mítico, el mejor gobernante será el que más cerca esté de esa divinidad arcaica y poderosa, siempre actualizada filosóficamente, para librarnos de los problemas de la democracia, en una época en que Platón se hace eco filosófico y político del desastre acaecido a su polis tras la Guerra del Peloponeso.

El Político sirve así de puente entre la idea del gobierno de los filósofos, que se expone en la República, y la de la necesidad de unas leyes fijas e inmutables, basadas en modelos divinos, de las Leyes. El gobernante mediador en la sociedad, a imagen de los legendarios legisladores, como Minos o Licurgo, se va configurando aquí como un hombre providencial. Se habla de una profesión de la política, que se ejerce como un saber basado en una amplia formación y experiencia (episteme):

"Entonces, necesariamente de entre los regímenes políticos, el más recto por excelencia y el único que puede serlo es aquel en el que se puede descubrir que quienes gobiernan son verdaderamente poseedores de una ciencia y no solo supuestamente, ya sea que gobiernen por medio de leyes o sin leyes, con el consentimiento de los gobernados o por imposición, ya sean pobres o ricos, nada de ello importa para determinar su rectitud." (Platón, Político 293e).

En el Político, en fin, se apunta la idea-luego desarrollada en las Leyes- de que, en espera de un rey filósofo, debemos contentarnos con el imperio de una ley basada en el conocimiento. Más importante que el político son las leyes que se implantan en la comunidad y el verdadero arte político es el de la legislación. La estructura del diálogo, dirigida hacia la determinación de quién es y cómo debe ser el político mediante un método dialogado de dihairesis en pos de la definición del politikos, llega a la conclusión, tras las metáforas del pastor y del tejedor y por medio del recurso al mito de la edad de oro, de la necesidad del gobierno a través de una episteme lógicamente emparentada con el saber mítico de los legisladores que lo heredan de aquel mundo áureo: el verdadero hombre de estado se perfila como un hombre regio cuya palabra se convierte en derecho 
y que gobierna en virtud de un conocimiento, revelado gracias a la filosofía, de índole superior y muy cercano al bien divino. En el pensamiento político del último Platón -entendido como el proyecto de ciudad y gobernantes ideales que se empieza a vislumbrar en el Político y llega a su máxima concreción en las Leyes-, se tiende, si nuestra hipótesis no está equivocada, a una equiparación cada vez más visible entre el político, el legislador, el filósofo y el mediador religioso.

\section{Bibliografía}

Alvarado planas, J. (1993). De la ideología trifuncional a la separación de poderes. Madrid, Universidad Nacional de Educación a Distancia.

Baldry, H.C. (1952), "Who invented the Golden Age", Classical Quarterly 2 1/4, 83-92.

BauzÁ, H.F. (1993), El imaginario clásico: edad de oro, Utopia y Arcadia, Santiago de Compostela, Universidade de Santiago de Compostela.

BerTelli, L. (1973), Gli utopisti greci : raccolta di testi tradotti. Torino, Litografia artigiana $M \& S$.

Brisson, L. (1987), "Proclus et l'Orphisme”, en Proclus. Lecteur et interprète des Anciens. Colloques internationaux du C.N.R.S., Paris, CNRS, 43-104.

- (1992), "Le corps «dionysiaque». L'anthropogonie décrite dans le Commentaire sur le Phédon de Platon (1, par. 3-6) attribué à Olympiodore est-elle orphique ?", en Chercheurs de sagesse. Hommage à Jean Pépin, Collection des Études Augustiniennes. Série Antiquité-131, Paris (Institut d'Études Augustiniennes), 481-499.

- (19983), Le même et l'autre dans l'estructure ontologique du Timée du Platon, Sankt Augustin, Academia Verlag.

- (1995), "Intérpretation du mythe du Politique", en C. Rowe (ed.), Plato: Statesman, Edited with an Introduction, Translation and Commentary. Warminster, Aris \& Phillips Ltd, 1995.

- (2005), "Un monde abandonné à lui-même", en Agonistes. Essays in honour of Denis O'Brien, edited by John Dillon and Monique Dixsaut, Aldershot / Burlington [VT] (Ashgate), 25-36.

Brisson, J.-P. (1988), “Rome et l'âge d'or: Dionysos ou Saturne?”, Mélanges de l'École française de Rome 100, 917-982. 
Castoriadis, C. [2004], Sobre el politico de Platón, Madrid, Trotta [trad.esp. de Sur le Politique de Platon, Paris, Éditions du Seuil 1999].

Collin, R. J., "Plato's Use of the Word MANTEYOMAI" Classical Quarterly, New Series, 2 (1952), 93-96.

Detienne, M. (1972), "Entre bêtes et Dieux", Nouvelle Revue de Psychanalyse VI, 23046.

-, (1977), Dionysos mis à mort, París, Gallimard.

Duke, E.A. et al. (eds. 1993), Platonis Opera I, Oxford, Oxford Classical Texts.

DumÉzIL, G. (1941), Jupiter-Mars-Quirinus. Essai sur la conception Indo-Européenne de la société et sur les origines de Rome. Paris, Gallimard.

- [1999], Los dioses soberanos de los indoeuropeos, Barcelona, Herder [trad. esp. de Le dieux souverains des Indo-Européens, Paris, Gallimard, 1977].

El murR, D. (2010), "Hesiod, Plato, and the Golden age: Hesiodic motifs in the myth of the Politicus", en G.R. Boys-Stones \& J.H. Haubold (eds.), Plato and Hesiod, Oxford: Oxford Univ. Press, 2010, 276-297

- (2014), Savoir et gouverner: essai sur la science politique platonicienne. Tradition de la pensée classique. Paris, Librairie Philosophique J. Vrin.

Fortenbaugh, W.W. \& Schütrumpf, E. (2001), Dicaearchus of Messana: Text, Translation, and Discussion (Rutgers University Studies in Classical Humanities, 10), New Brunswick, NJ.

FräNKel, H. (1993), Poesía y filosofía en la Grecia arcaica, Madrid, Visor [trad. esp. de Wege und Formen des frühgriechischen Denkens. Literarische und philosophiegeschichtliche Studien. München, C. H. Beck, 1955].

Fernández Galiano, M. (ed. 1992), Píndaro, Olímpicas, Madrid, Ediciones Clásicas (Bibliotheca Graeca).

GaISER, K. (1968). Platons ungeschriebene Lehre. Studien zur systematischen und geschichtlichen Begründung der Wissenschaften in der Platonischen Schule. E. Klett, Stuttgart.

González Laso, A. (ed. 1994), Platón, El Politico, Critón, Menón, Madrid, Centro de estudios constitucionales.

Goodrich, W. J. (1906), "Plato, Politicus 269 E-270 A: An Allusion to Zoroastrianism?”, The Classical Review, 20.4, 208-209

Griffiths, J.G. (1958), “Did Hesiod invent the Golden Age?”, Journal of the History of Ideas 19.1/4, $91 \mathrm{y}$ ss.

Hernández de la Fuente, D. (2009), "La edad de oro dionisíaca: una utopía entre religión y política" Quaderni del Dipartimento di Filologia Linguistica e Tradizione Classica "Augusto Rostagni" dell'Università di Torino 8 (2009) 97-116. 
- (2013), "Der Chor des Dionysos: Religion und Erziehung in Platons Nomoi", Zeitschrift für Religions- und Geistesgeschichte 65.1 (2013) 1-17.

Horn, C. (2002), "Warum zwei Epochen der Menschengeschichte? Der Mythos im Politikos", en M. Janka \& Schäfer, C., Platon als Mythologe Neue Interpretationen $z u$ den Mythen in Platons Dialogen, Darmstadt, Wissenschaftliche Buchgesellschaft. 139-159.

Lesky, A. (1969), Historia de la literatura griega, Madrid, Gredos, 1969 [trad. es. Geschichte der Griechischen Literatur, Bern 1963²].

Lisi, F.L. (1985), Einheit und Vielheit des platonischen Nomosbegriffes. Eine Untersuchung zur Beziehung zswischen Philosophie und Politik bei Platon. Königstein / Taunus (Beiträge zur klassischen Philologie, Heft 167).

- (ed. 1999a), Platón, Diálogos VIII (Leyes I-VI), Madrid, Gredos, 1999.

-, (ed. 1999b), Platón, Diálogos IX (Leyes VII-XII), Madrid, Gredos, 1999.

-, (2004), "El mito del Político", Études Platoniciennes I, 73-90.

-, (2015), Reseña a D. El Murr, Savoir et gouverner : essai sur la science politique platonicienne. Tradition de la pensée classique. Paris: Librairie Philosophique J. Vrin, 2014, en Bryn Mawr Classical Review 2015.09.14.

Montserrat Molas, J. (2014), “La utopia correctora. A propòsit del mite d'El polític de Plató", Studia philologica valentina (De republica instituenda: Les utopies politiques clàssiques en la construcció de la societat moderna), 16 (2014), 91-112.

Mazon, P. (ed. 1951), Hesiode, Théogonie; Les travaux et les jours; Le bouclier. París, Les Belles Lettres.

Neyton, A. (1984), L'âge d'or et l'âge de fer, París, Les belles lettres.

Pabón J. M. y M. Fernández Galiano (eds. 1993), Platón, La República. Introducción de Emilio García Díaz. Colección "Nuestros Clásicos". Universidad Nacional de México.

Quandt, W. (ed. 1962), Orphei Hymni, Berlin, Weidmann.

Robinson, T. M. (1967), "Demiurge and World Soul in Plato's PoliticusDemiurge and World Soul in Plato's Politicus", The American Journal of Philology 88.1, 57-66.

Rowe, C. (1999), Plato: Statesman, Indianapolis, Hackett publ.

- (2002) "Zwei oder drei Phasen? Der Mythos im Politikos", en M. Janka \& Schäfer, C., Platon als Mythologe Neue Interpretationen zu den Mythen in Platons Dialogen, Darmstadt, Wissenschaftliche Buchgesellschaft. 160-175.

- (2010), "On the grey-haired babies: Plato, Hesiod and visions of the past (and the future)", en G.R. Boys-Stones \& J.H. Haubold (eds.), Plato and Hesiod, Oxford: Oxford Univ. Press, 298-316. 
Santa cruz, Ma I., "Racionalidad y mecanismo. Una lectura de Político y Leyes X", Estudios de Filosofia 26 (2002), 27-42.

Santa Cruz, Ma I. et al. (ed. 1988), Platon, Diálogos V (Parménides Teeteto, Sofista, Político), Madrid, Gredos.

Saunders, T.J. (2001), "Dicearchus' Historical Anthropology", en W.W. Fortenbaugh \& E. Schütrumpf (eds. 2001), 237-254.

Skemp, J.B. (1952), Plato's Statesman, Londres.

Thury, E.M. (1998), "A study of words relating to youth and old age in the plays of Euripides and its special implications for Euripides' Suppliant Women", Computers and the Humanities, 22.4, 293-306.

Van Noorden, H. (2015), Playing Hesiod: The 'Myth of the Races' in Classical Antiquity. Cambridge Classical Studies. Cambridge: Cambridge University Press, 2015.

Vernant, J.-P. [2001], "Estructuras del mito: El mito hesíodico de las razas. Ensayo de análisis estructural", en Mito y Pensamiento en la Grecia Antigua, Madrid, Akal [trad. esp. de "Le mythe hésiodique des races. Sur un essai de mise au point" en Mythe et pensée chez les Grecs, 1985, 19-45].

VIDAL-Naquet, P. (1978), "Plato's Myth of the Statesman. The ambiguities of the Golden Age and of history", Journal of Hellenic Studies 98, 132-141.

- [1983], "Tiempo de dioses y tiempo de hombres", en Formas de pensamiento y formas de sociedad en el mundo griego: el cazador negro. Barcelona, Península [trad. esp. de Le chasseur noir: formes de pensée et formes de société dans le monde grec, París, Maspero, 1980].

Enviado : 4/01/2014

Recibido : 17/03/2014

Este trabajo se encuentra bajo una licencia de Creative Commons Reconocimiento-NoComercial-SinObraDerivada 4.0 Internacional

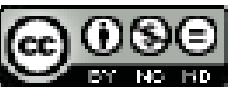

